\title{
Telemonitoring of Three Characteristic Parameters of Acoustics Vocal Signal in Patients with Tumor or Inflammatory Chronic Dysphonia
}

S Abdelouahed ${ }^{1 *}$, M Benabdellah $^{1}$ and S Aounallah ${ }^{2}$

${ }^{1}$ Laboratory of Biomedical Engineering, Tlemcen University, Tlemcen, Algeria

${ }^{2}$ Specialist in Oto-Rhino-Laryngology (ORL), Assistant at Tlemcen University, Tlemcen, Algeria

\begin{abstract}
The evaluation of voice quality and the perception of its degradation through various acoustic clues are major concerns for voice professionals involved in the process of vocal rehabilitation. In this context, it is necessary to pay particular attention to the set of indices capable of delivering relevant information to help diagnose and assess the effects of vocal re-education proposed. Therefore, the contribution of experimental phonetics in clinical practice is a proven fact. If the study we propose is part of the evaluation of voice quality, our problem is to develop a system dedicated to the objective characterization of chronic dysphonia of tumor or inflammatory origin. The aim of the telemedicine device that we develop is threefold: diagnosis, treatment and monitoring of disease. For this we proceed initially to the remote recording and archiving of an acoustic speech signal voiced in this case "a" sustained for three seconds. We then apply at the ENT department of the University Hospital of Tlemcen, different algorithms of objective assessment of three parameters in this case the fundamental frequency, jitter and DFT-RD that allow experts to assess the development of chronic dysphonia of tumor or inflammatory origin (larynx cancer, inflammatory polyp of the vocal cords, chronic laryngitis).
\end{abstract}

Keywords: Télé medicine; DFT-RD; Chronic dysphonia; Voised sound; Jitter; Fundamental frequency; Winsock

\section{Introduction}

The voice is a spectacular indicator of physical and mental health of a person. The technology of voice pathology has been a marked increase over the past two decades, the voice processing is now a fundamental component of engineering [1-4].

The special importance of voice processing in the more general framework is due to the privileged position of the speech as a vehicle of information in our human society [5]. The voice is indeed produced by the vocal tract, continuously monitored by the motor cortex [6,7].

Among the voice treatment applications we distinguish $[8,9]$;

1) Temporal spatio-spectro analysis of the vocal signal observing the objective characterization of dysphonia of laryngeal origins $[6,10]$.

2) Quantitative estimation of characteristics parameters of the vocal signal during its acoustical representation Including the Fundamental Frequency and the jitter of voiced sounds [11].

\section{Materiel and Methods}

The slide that we have implemented is composed of an interface for acquiring the acoustic speech signal consists of a classic microphone to reproduce sound in analog form and sound card for digitization and the environment "Audacity "as software to archive the signal in Wave format in order to perform the calculation of different indices and we had to implement an algorithm for converting Wave format to decimal format in Visual Basic environment. The experimental protocol includes the following steps:

- Pronunciation of a voiced sound in this case 'a' sustained for three seconds.

- The division of the signal into 6 frames each 0.5 seconds

- The calculation of the three indices (spectral content, fundamental frequency and jitter) averaged over six frames.
- The correlation between the indices themselves and the balance sheet and para-clinic of patients.

- The implementation of an interactive database of physiological and pathological acoustic voice signals for a clinical and epidemiological study and better therapeutic management.

\section{Global algorithm of the application}

Recording the vocal signal via Audacity software

Data conversion from the WAVE format to hexadecimal one

The signal windowing

The signal layout

The Calculation and the layout of the DFT

Calculation of jitter

Calculates the average fundamental frequency (Table 1)

The fundamental frequency is established by gliding average method $[12,13]$ is given by following equation

\section{Distant Sustained of the Patient}

The patient treated by the radiotherapy (persons suffering from

*Corresponding author: S Abdelouahed, Laboratory of Biomedical Engineering and Tlemcen University, Tlemcen, Algeria, Tel: 002134328 5689; E-mail: sara.abdelouahed@hotmail.com

Received September 11, 2013; Accepted December 23, 2013; Published December 29, 2013

Citation: Abdelouahed S, Benabdellah M, Aounallah S (2013) Telemonitoring of Three Characteristic Parameters of Acoustics vocal signal in patients with Tumor or Inflammatory Chronic Dysphonia. J Health Med Informat 4: 142. doi:10.4172/21577420.1000142

Copyright: ( $) 2013$ Abdelouahed S,et al. This is an open-access article distributed under the terms of the Creative Commons Attribution License, which permits unrestricted use, distribution, and reproduction in any medium, provided the original author and source are credited. 
Citation: Abdelouahed S, Benabdellah M, Aounallah S (2013) Telemonitoring of Three Characteristic Parameters of Acoustics Vocal Signal in Patients with Tumor or Inflammatory Chronic Dysphonia. J Health Med Informat 4: 143. doi:10.4172/2157-7420.1000143

Page 2 of 3

\begin{tabular}{|c|c|c|c|c|c|c|c|c|c|c|}
\hline \multicolumn{11}{|l|}{ Healthy subjects } \\
\hline $\begin{array}{l}\text { Fundamental } \\
\text { frequencies Fs (HZ) }\end{array}$ & $1^{\text {st }}$ subject & $2^{\text {nd }}$ subject & $3^{\text {rd }}$ subject & $4^{\text {th }}$ subject & $5^{\text {th }}$ subject & $6^{\text {th }}$ subject & $7^{\text {th }}$ subject & $8^{\text {th }}$ subject & $9^{\text {th }}$ subject & $10^{\text {th }}$ subject \\
\hline \multicolumn{6}{|c|}{ Male sex } & \multicolumn{5}{|c|}{ Female sex } \\
\hline $1^{\text {st }}$ selection & 227.05 & 200.65 & 190.09 & 184.81 & 216.49 & 205.93 & 184.81 & 211.21 & 200.65 & 190.09 \\
\hline $2^{\text {nd }}$ selection & 184.81 & 211.2 & 184.8 & 211.21 & 184.81 & 179.53 & 205.93 & 190.09 & 211.2 & 184.8 \\
\hline $3^{\text {rd }}$ selection & 184.81 & 184.8 & 184.8 & 179.53 & 200.65 & 221.77 & 227.05 & 195.37 & 184.8 & 184.8 \\
\hline $4^{\text {th }}$ selection & 227.05 & 184.8 & 216.49 & 184.81 & 221.77 & 205.93 & 211.21 & 216.49 & 184.8 & 216.49 \\
\hline $5^{\text {th }}$ selection & 195.12 & 211.4 & 184.81 & 211.21 & 200.65 & 184.81 & 195.37 & 179.53 & 184.81 & 184.81 \\
\hline $6^{\text {th }}$ selection & 184.8 & 195.37 & 211.21 & 184.8 & 184.81 & 205.93 & 195.37 & 195.37 & 195.37 & 211.21 \\
\hline $\begin{array}{l}\text { The average } \\
\text { fundamental } \\
\text { frequencies }(H Z)\end{array}$ & 200.6 & 198.03 & 196.68 & 192.72 & 201.53 & 200.65 & 203.29 & 198.01 & 193.59 & 195.36 \\
\hline Jitter (sec) & 0.69 & 0.67 & 0.68 & 0.67 & 0.77 & 0.68 & 0.61 & 0.79 & 0.7 & 0.68 \\
\hline
\end{tabular}

Table 1: The jitter and the average fundamental frequency in healthy subjects of corpus.

\begin{tabular}{|c|c|c|c|c|c|c|c|c|c|c|}
\hline \multicolumn{11}{|l|}{ Sick subjects } \\
\hline $\begin{array}{l}\text { Fundamental } \\
\text { frequencies Fs }(\mathrm{HZ})\end{array}$ & $1^{\text {st }}$ subject & $2^{\text {nd }}$ subject & $3^{\text {rd }}$ subject & $4^{\text {th }}$ subject & $5^{\text {th }}$ subject & $6^{\text {th }}$ subject & $7^{\text {th }}$ subject & $8^{\text {th }}$ subject & $9^{\text {th }}$ subject & $10^{\text {th }}$ subject \\
\hline \multicolumn{6}{|c|}{ Pathologietumorale } & \multicolumn{5}{|c|}{ Pathologieinflammatoire } \\
\hline $1^{\text {st }}$ selection & 73.92 & 58.08 & 68.64 & 47.52 & 47.52 & 50.52 & 105.6 & 121.44 & 105.6 & 174.25 \\
\hline $2^{\text {nd }}$ selection & 73.92 & 47.52 & 47.52 & 52.8 & 63.36 & 67.36 & 147.85 & 105.6 & 137.29 & 163.69 \\
\hline $3^{\text {rd }}$ selection & 52.8 & 47.5 & 47.52 & 52.8 & 47.52 & 50.52 & 126.73 & 110.88 & 126.73 & 142.57 \\
\hline $4^{\text {th }}$ selection & 73.92 & 42.24 & 68.64 & 47.58 & 58.08 & 58.08 & 142.57 & 100.32 & 110.88 & 174.81 \\
\hline $5^{\text {th }}$ selection & 63.36 & 42.24 & 68.64 & 58.08 & 63.36 & 68.64 & 105.6 & 137.29 & 121.44 & 163.69 \\
\hline $6^{\text {th }}$ selection & 73.92 & 47.52 & 73.92 & 58.08 & 68.64 & 47.52 & 110.88 & 137.29 & 105.6 & 142.57 \\
\hline $\begin{array}{l}\text { The average } \\
\text { fundamental } \\
\text { frequencies }(\mathrm{HZ})\end{array}$ & 68.64 & 47.51 & 62.48 & 52.81 & 58.08 & 57.10 & 123.20 & 118.8 & 117.92 & 160.17 \\
\hline Jitter (sec) & 2.64 & 2.22 & 2.62 & 2.4 & 2.69 & 2.65 & 1.5 & 1.59 & 1.55 & 1.03 \\
\hline
\end{tabular}

Table 2: The jitter and the average fundamental frequency in sick subjects of corpus.

cancer) or by medical treatment (a patient presents a clinical inflamed syndrome) and whose living in isolated area especially the north polar could be distant sustained thank to platform implantation at near the health centers and thanks to the periodical recording of the acoustical signal vocal according to the precedent described protocol and its O.R.L department of University Hospital accordance with the architecture client-server hold up by the component Winsock compatible with the protocol TCP/IP which permitted the transmission of the data toward intranet or internet thus the patient avoiding the inutile movement a condition that he responds favorably to the instituted treatment.

\section{Summary of Results}

In healthy subjects the fundamental frequency is situated around $200 \mathrm{~Hz}$ corresponding to the physiological frequency of the vowel 'a'. Jitter extend to $0.7 \mathrm{sec}$ (Table 2).

In patients with cancer of the vocal cords the fundamental frequency is significantly reduced by around $60 \mathrm{HZ}$ against jitter is greatly increased set to $2.5 \mathrm{sec}$.

- In patients with inflammatory disease: chronic laryngitis: fundamental frequency is reduced to $120 \mathrm{HZ}$. Jitter is increased slightly to $1.5 \mathrm{sec}$.

- Inflammatory polyp of the vocal cords: fundamental frequency decreased slightly to $160 \mathrm{HZ}$. Jitter is increased slightly to $1.03 \mathrm{sec}$.

The spectral range is also significantly diminished in cancer patients due to the large reduction see the total absence of vibration of the vocal cords. This limitation of the frequency content is also present but truncated in the case of chronic inflammatory diseases of the larynx.

\section{Conclusion}

Characterization and objective assessment of chronic dysphonia using three parameters study seems to be in perfect harmony in effect in the case of inflammatory diseases the fundamental frequency is around $120 \mathrm{HZ}$ and jitter around $1.2 \mathrm{sec}$;. While in tumor pathologies fundamental frequency is much lower (goshawks $60 \mathrm{HZ}$ ) while the jitter increases to three times compared to healthy subjects $(2.5 \mathrm{sec})$.

The clinical and para-clinical examination and notably the pathological examination are in perfect agreement with the evolution of its indices.

Clinical validation of the results is still subject to a much larger sample supported by a rigorous statistical support.

\section{References}

1. Benlaldj L (2000) Etude de la méthode PLP (Perceptual linear prediction) en reconnaissance automatique de la parole, Thèse de magister en électronique, spécialité : Signaux et Systèmes, promotion 1999/2000.

2. Giovanni A, Estublier N, Robert D, Teston B, Zanaret M, et al. (2003)Objective vocal evaluation of dysphonia by simultaneous measurement of acoustic and aerodynamic parameters with the EVA device.Ann Otolaryngol Chir Cervicofac 112: 85-90.

3. Emmanuelle Guibert (2006) Caractéristiques physiques et auditives d'un signal sonore. 1-7.

4. (1998) Ecole Polytechnique Fédérale de Lausanne. EPFL.

5. Giovanni A, Yu P, Révis J, Guarella MD, Teston B, et al. (2006) Analyse objective des dysphonies avec l'appareillage EVA. Etat des lieux." Revue OtoRhino-Laryngologie Française 90: 183-192. 
Citation: Abdelouahed S, Benabdellah M, Aounallah S (2013) Telemonitoring of Three Characteristic Parameters of Acoustics Vocal Signal in Patients with Tumor or Inflammatory Chronic Dysphonia. J Health Med Informat 4: 143. doi:10.4172/2157-7420.1000143

Page 3 of 3

6. Ghio A, Pouchoulin G, Giovanni A, Fredouille C, Teston B, et al. (2008) Approches complémentaires pour l'évaluation des dysphonies: bilan méthodologique et perspectives. Travaux Interdisciplinaires du Laboratoire Parole et Langage d'Aix-en-Provence (TIPA) 26: 33-74.

7. Jacques Génin (1989) la parole et son traitement automatique, Ed. Masson. La parole et son traitement automatique Calliope. Annales des Télécommunications 45: 457-458.

8. Dutoit T (2000) Introduction au Traitement Automatique de la Parole », Notes de cours, Faculté Polytechnique de Mons.

9. Andrzej Drygajlo, Traitement De La Parole (2000)“Interactive Multimodal Information Management (IM)2", Laboratory of IDIAP (LIDIAP) Institute of Electrical Engineering (IEL),Swiss Federal Institute of Technology.
10. Yu P, Garrel R, Nicollas R, Ouaknine M, Giovanni A (2007) Objective voice analysis in dysphonic patients: new data including nonlinear measurements. Folia Phoniatr Logop 59: 20-30.

11. Camille Finck, chapitre sur L'évaluation fonctionnelle des dysphonie d'origine laryngé, Service d'Oto-rhino-laryngologie, CHU sart Tilman, Université de Liège, Liège, Belgium.

12. Lakhdar Mohammed Hicham, Hassam Ahmed (2001) classification des sons de la parole par la technique PLP », Mémoire de fin d'étude pour l'obtention du diplôme d'ingénieur d'état en contrôle, Université Abou Beker Belkiad Telemcen.

13. Teston BL (2004) évaluation instrumentale des dysphonies. Etat actuel et perspectives. In Giovanni A. (ed.) Le bilan d'une dysphonie. ISBN 2-91451362-3. Marseille: Solal 105-169. 